\title{
The Ethical Dilemma of Information Asymmetry in Innovation: Reputation, Investors and Noise in the Innovation Channel
}

\author{
Carla Millar, Yuri Udalov and Hartley Millar
}

\begin{abstract}
A sufficient and steady stream of innovations is widely seen as a basis for healthy modern economies. Governments divert substantial resources from other purposes in society to increase innovation. Yet the failure rate among innovative SMEs is high, suggesting that resources are wasted. Avoiding such waste is a challenge for both governments and investors, but also raises a question for the innovative company, namely how to build and fund the enterprise on an ethical basis. The dilemma of giving in to temptations to 'cut corners' clearly exists, for example to exploit the inevitable asymmetry of information arising in innovation and potentially deploy this in support of misleading claims about specific capabilities and/or the unjustified creation and exploitation of reputation. This is consistent with Olaf Fisscher's finding that entrepreneurs starting new ventures tend to exhibit an inherent bias towards compromising their own values in order to succeed at any cost. When the innoSME's aspirations are unrealistic or the proposed innovations are of marginal value, the ethical issues are broader and extend also to those who are potential financiers. Noting this as a gap in the ethics literature, we argue that the current situation fails to match economic and ethical ideals and that work is needed to develop tools which allow those who provide finance and support for innovation to target it more effectively at those who have a prospect of successfully launching genuine innovations and thus reduce the 'noise' in the innovation field.
\end{abstract}

\section{Introduction}

Tt has long been widely recognized that a sufIficient and steady stream of innovations is required for the sustainability of modern economies (Schumpeter \& Opie, 1934; Aghion \& Griffith, 2008). This depends upon innovative companies being able to generate good returns from their efforts and on investors (or governments) being successful in their efforts to direct resources to the innovative companies that can best make use of them. However, the failure rate among innovative SMEs (innoSMEs) is high (Luo \& Mann, 2011). In this paper we focus on the relationship of innoSMEs with sources of finance (investors or governments) and explore how the information asymmetry that is inherent in the nature of innovation means that investors and government agencies are at risk of being misled - whether deliberately or not - and entrepreneurs are at risk of slipping into unethical behaviour.

The results of such deception - or failure by investors to deal adequately with information asymmetry - are evident in the numerous examples of innoSMEs which receive funding and fail. We consider the mechanisms relied on to overcome the penalty of information asymmetry and in particular the potential for SMEs' efforts using mechanisms such as reputation to result in the misallocation of resources in innovation support regimes. We argue that there is an ethical as well as an economic imperative to counter this, since the resources could be better applied elsewhere, the openness of investors and society to innovations is reduced and there is much personal pain involved in pursuing business start-ups that fail.

We raise the question whether it is possible for investors to recognize earlier and better 
innovative SMEs whose poor prospects are disguised by misleading information (deliberate if not false). To illustrate this, we consider a typology which emerged from a performance analysis of a sample of 120 innoSMEs, part of a wider piece of research into the evaluation of investment strategies (Millar \& Udalov, 2011). This highlights the problem of how to avoid encouraging (through finance) those which have minimal prospects of success; they take up evaluation resources not to mention finance and can therefore be seen as causing 'noise' in the system.

The consequence of conscious or unconscious misleading of investors is that potentially successful companies miss out on necessary funding. It also contributes to the high overall failure rate of innovative SMEs and we believe that this in turn erodes confidence in investment in innovation, resulting in higher financing costs and greater public scepticism.

Our conclusion is that the information asymmetry that is inherent in the innovation context creates a temptation for unethical behaviour and that reputation ceteris paribus is an inadequate basis for making investment or purchasing decisions. The typology of innovative SMEs we have developed highlights the groups which may benefit from ignoring this, and underpins the view that it can lead to an allocation of resources which breaches the objective of maximum sustainability. Further research may throw light on the early warning signs that can indicate probable failure and help counteract rent-seeking through reputational hype.

The objective of this paper is, through addressing a lesser covered part of the ethics literature, to position information asymmetry as a central problem in achieving a fair distribution of innovation support, and to emphasize that efforts to overcome this have ethical dimensions as well as economic ones. The intrinsic information asymmetry can be exploited and the entrepreneur's method of seeking funding has ethical dimensions; those who fund and encourage entrepreneurs thus also need to be aware of whether their input is contributing to an ethically unacceptable outcome.

Our research addresses a gap in the literature in that academic attention to ethical challenges facing innovative entrepreneurs tends to focus on issues such as attitude to ethics (e.g., Christensen, Schwartz \& Hoss, 2008), or on the extent and motivation for behaviour in specific areas of potential illegality such as intellectual property rights, insider information and money-raising practices (e.g., Fassin, 2000). By contrast our discussion highlights how a specific aspect of the environment of the innovative firm generates specific ethical challenges; these emerge because entrepreneurs develop tools and techniques which will help them to communicate what they wish - and to conceal what they wish to hide; with such mechanisms available to them there is a natural temptation for:

1. misrepresentation by way of 'hype' in relations with stakeholders, especially investors and grant givers,

2. manipulative exploitation of reputation and reputational networks,

3. appropriation of resources that could be better deployed elsewhere, thus reducing the benefit of these resources to society.

We also note that the activities of enthusiastic innovator-entrepreneurs may also be ethically questionable when they result in:

1. helping establish as the norm the pursuit of quick returns, i.e. excess and rapid 'rents' arising from the innovations; such a norm is of debatable value and may undermine the position of those who expect reward only for steady patient effort, and

2. avoidable pain and suffering, including financial, to those who devote their time and allegiance to innovative enterprises that have only a marginal chance of success.

\section{Perspective}

As noted above, most western countries accept that small and medium-sized enterprises are a key source of innovations and see it as important to channel funding to them, by encouraging venture capital (VC) investment and bank loans, by making grants or offering tax concessions. It is important that this transfer of resources benefits those SMEs whose businesses are sustainable sources of valuable innovations and hence it is important that investors are able to judge which these are. A solid policy for innovation depends upon success in such identification and, as innovations are implicitly experience, credence or societal (Darby \& Karni, 1973; Millar, 2004) goods, this depends on how investors deal with information asymmetry.

The desired stream of innovations is dependent on individuals and organizations taking decisions of two sorts, either to seek investment or to provide funds. Those faced with these decisions may see them as ethically neutral but in fact the decisions have more than economic consequences. There are social consequences which flow from the success or failure of innovative enterprise, and adding to the extent of these is not an ethically neutral 
matter. Nor is the behaviour of those seeking funding. Furthermore, in broad socioeconomic terms, there are issues about how resources are allocated and about what sort of society is created; for example, one with an emphasis on rapid accumulation of wealth is different from one with more conservative values.

In considering such issues it is important to clarify what we mean by innovation and the key perspectives we will adopt. One of the first economists to pay attention to the crucial role of innovation was Schumpeter, who also coined the phrase 'disruptive innovation'. He pointed out the difference between new or improved products, new production techniques, new markets and new ways to organize the business (Schumpeter \& Opie, 1934). In a concise form this was repeated by Freeman who clarified the concept of an innovation as: 'An innovation in the economic sense is accomplished only with the first commercial transaction involving the new product, process, system or device, although the word is also used to describe the whole process' (Freeman \& Soete, 1997). As it contains a balanced combination of technology, economics and business we will adopt this definition and also bear in mind that it is a serious mistake to treat an innovation as if it were a well-defined, homogeneous thing that could be defined as entering at a precise date or becoming available at a precise point in time' (Kline \& Rosenberg, 1986).

Innovation is thus a process in society; it presents the actors involved - entrepreneurs, financiers, customers - with the question whether what they are doing is ethical. We focus on the relationship between the innovative company and its sources of finance which we usually term 'investors', but include both those who provide equity or loans and those (e.g., government agencies) who provide grants or incentives through the tax regime. Attention to ethics requires not only a consideration of the innovation itself but also of how society's resources are allocated. While most comment on this relates to allegedly excessive levels of new product introduction, we believe that attention also needs to be given to the impact of abortive investments, many of which never even reach the public.

Thus there are wider ethical aspects to the situations that arise. We do not believe that the differences among the variety of ethical systems proposed in a business context make a great difference to our observations, but for the sake of clarity we shall work with a 'ruleutilitarian' ethic which places the highest value on the achievement of outcomes beneficial to human society, but combines this with the need to seek out rules of conduct and which thereby 'does a better job than its rivals of matching and tying together our moral convictions, as well as offering us help with our moral disagreements and uncertainties' (Hooker, 2000).

\section{What makes for Successful Innovation?}

Fundamental to an understanding of how innovation operates is the answer to the simple question: 'Why do people (try to) innovate?'. The simple answer is because they want to obtain an advantage: a competitive advantage that allows them to beat business rivals, and/or a social or personal advantage, which in the case of a technology-based firm may very well be psychological satisfaction for those behind the innovation(s). The measure of such advantage will be benefits to the innovator (Schumpeter \& Opie, 1934). For this reason innovators typically protect their intellectual property (IP) rights and know-how; they own the innovation and can either apply and implement it or drop it. Even despite patent protection, the innovator in an $\mathrm{SME}^{1}$ will normally release only as much information about how the innovation is achieved as is necessary (Jeon \& Menicucci, 2008). We recognize that some academics as well as businessmen advocate the concept of 'open innovation' (Chesbrough, 2003), originally introduced in the 1960s. However, as evidenced by the cases covered in a Special Issue of RED Management (Enkel, Gassmann \& Chesbrough, 2010), this is a trend that has yet to become dominant, i.e., the majority of both the business community and investors still support the closed innovation approach which is hence the paradigm in our analysis. For such situations there is an inherent driver to maintain the position in which the innoSME 'knows the secret' and it remains less well understood by the external environment, including (potential) investors. For the investor it is important to predict, before making a commitment, whether an innovation will be successful; the risk is that otherwise time, money and commitment devoted to the innovation will be wasted. In the case of innovative SMEs, the success of the firm and the success of the innovation are intimately connected.

It is well established that for innovation (and the company that brings innovation to life) to be successful, a combination of qualities has to be present in both internal and external environments (Bartoloni, 2011). Griffith and Webster (2010) attempted to estimate the separate effects of internal versus external environ- 
mental factors on R\&D activity; to this must be added the issue of timing on which Forsythe and Khormaei (2011) write explicitly: 'A key failure mode for businesses of all sizes is application of an otherwise good innovation strategy at the wrong time'.

We posit that in order to succeed, the innoSME should possess all of the following internal competencies and advantages:

1. The brilliant idea, including technological (scientific) advantage and competencies.

2. Business and management advantage and competencies.

3. Financial advantage and competencies.

At the same time, the company should be embedded in an environment that provides it with supportive external advantages, and the innovation must take place

4. at the right time, in the right place, and within the right competitive environment.

If all these four boundary conditions are fulfilled, such a company is in a position to succeed with a possibly ground-breaking innovation. Such a combination of conditions is, however, very rare, and one of the biggest problems for investors is that this comes to light not when the innovation proposal is brought to them, but only when it has become a success. A sustainable policy for innovation depends upon success in such identification and we submit that understanding and dealing with the barriers that prevent such identification can contribute to successful investment. We therefore consider the issue of information asymmetry which is such a barrier.

\section{Information Asymmetry in the Innovation Arena}

'Information asymmetry' manifests itself in a transaction situation whenever the value of a product or service cannot be determined without trying, sampling or experiencing the good. Although 'information asymmetry' applies to any such good (e.g., raw diamonds; Berger \& Herstein, 2012), it is especially relevant to knowledge transfer (Millar, 2004), where the buyer cannot assess in advance what the knowledge transferred is worth. We posit that innovative products and the proposition of investing in a business that will depend on innovation are similarly hard for potential buyers or investors to assess and value, since the original and innovative aspects of the value of the innovation in practice are not observable by the investor while the business is only at the planning stage. This situa-

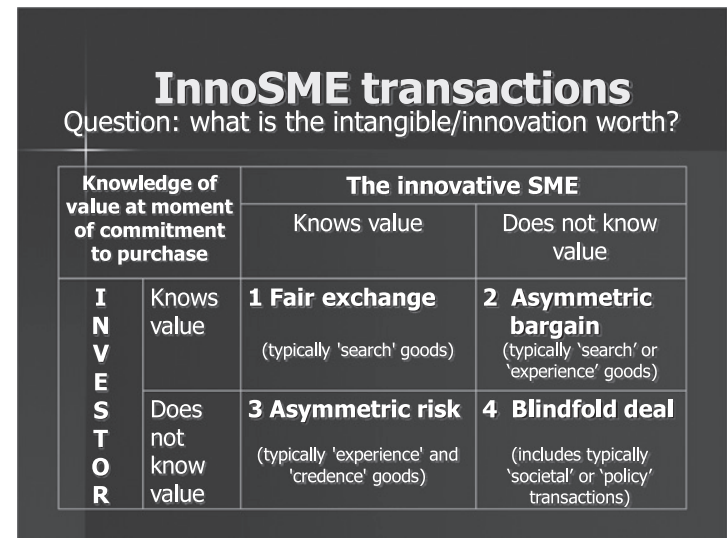

Figure 1. Asymmetry Matrix

tion is similar to any knowledge transfer involving experience, judgement, intuition, insights and values. Not only is the buyer of an innovative product or service facing incomplete and often asymmetric information about the product being transferred, he needs to use/experience it, i.e., embed it in the context of his own internal environment (Millar, 2004), and in this respect the investor is in a similar position to the customer or buyer.

Lin, Geng and Whinston (2005) researched the information structure of knowledge markets and the impact of information asymmetry on knowledge transfers, and proposed mechanisms to overcome the information asymmetry for effective communication. In a sense the product that is on offer from an innoSME, be it a tangible product or a service, also has the intangible characteristic of being innovative. Building on the research of Lin, Geng and Whinston, research and mapping out the information structure of senderreceiver in a marketing context, i.e., from marketer to customer, Millar (2004) developed a matrix covering that intangible element. This matrix has been adapted in Figure 1 for the current relationship between the InnoSME and the investor. This matrix gives rise to four different cases, clockwise:

- Field 1: Both the InnoSME and the investor are well informed about the value of the offering: it is a case of 'common knowledge' (Aumann, 1976). This applies to most search goods; however, branding and other nonmarket activities will make a difference affecting purchase behaviour.

- Field 2: The investor knows the value of the offering, but the innovator does not. This is rare but does happen; tragic cases see the light sometimes in the art and antiques markets, at times the investor has better market knowledge than the innovator, and 
a further famous example is when Bill Gates bought the DOS operating system from a Seattle programmer for $\$ 50,000$.

- Field 4: Neither the innovator nor the investor knows the true value of the offering this is a real case of incomplete information, and applies to a new category of goods, the category of 'societal' goods.

- Field 3: The innovator knows the value and the investor does not. This is the normal case of asymmetric knowledge, and applies to most credence goods. Innovations can often be seen as credence goods.

In the case of investments in innovations, asymmetry is especially present because

1. the true 'quality' of what is purchased/ invested in may only become apparent after the innovation has settled in through adoption and repeated use,

2. there are typically no similar products/ services which can be used as a benchmark - whether for price or characteristics, and

3 . very often the basis of the innovation is something sophisticated into the validity or value of which the investor has no insight.

An example of failure in the first category could be nylon bed sheets - which, in spite of their positive points on ease of washing and speed of drying, turned out not to be such a good innovation due to extensive problems when in use.

\section{Temptations arising from Information Asymmetry}

As early as the 1990s, Nayyar (1993) pointed to the opportunity for firms to profit from information asymmetry in the case of experience services. As argued above, information asymmetry also affects the relationships between innovative SMEs and those whose resources are used to launch or sustain them. Investors provide capital and governments and their agencies provide support, tax concessions and sometimes loans or grants. As noted, the problem of information asymmetry is particularly acute in the case of experience or credence goods/services (Darby \& Karni, 1973; Nayyar, 1993). The relationship between the innoSME and potential investors is similar to that of an experience service seller and customer - with the investor being the provider of money and the SME being the provider of a service in the form of a share in the success of the innovation(s).

Due to information asymmetry investors are at risk of being deceived - whether deliberately or not - about what the innovative SME is capable of achieving. Information asymmetry makes it difficult for investors and governments to be sure they are directing their support to SMEs that have genuine potential. With capital and support being limited resources it is important to avoid the available investment and support being diverted from the most promising innovators to those with less ability, poorer prospects, minor/ superficial innovations or fewer scruples.

Proprietorial secrecy about how innovations are achieved and how the company will be run constitutes a major barrier to those who wish to predict success. The only information that tends to be available is selective information about the company and subjective information about the innovation and its expected impact as published by the company. The question for investors is therefore to what extent it is possible to use information from and about the company to gauge the (market) prospects of the innovation and the survival chances of the company. The question for the company, however, is how it can control the information flow so as to maximize its ability to raise the funds it sees as desirable and this may involve concealing investor-deterring weaknesses, whether in the innovation or in the company itself.

In dealings with potential investors innoSMEs therefore deploy techniques to control information flows. Academic papers that consider information asymmetry in this context are apt to claim that the value of their findings includes the assistance they give to the entrepreneur to improve his/her success rate in acquiring funds, e.g., Kuratko and Brown (2010) who 'propose that these ventures are driven by a "quest for legitimacy" and that life sciences entrepreneurs therefore must be aware of the strategic issues which impact legitimacy in the eyes of external stakeholders (e.g., investors)'.

The ability of innoSMEs to use these and other approaches effectively and secure funding despite weaknesses that, if recognized, would have deterred investors, emerges from the results of a performance analysis of innoSMEs in the US and Europe that did secure funding for their innovation, in which companies were classified and a typology was developed reflecting the appropriateness of their having been funded (Millar \& Udalov, 2011).

\section{Typology}

There are many fortuitous and random factors which may cause a company to fail, and there are unforeseeable factors that contribute to 


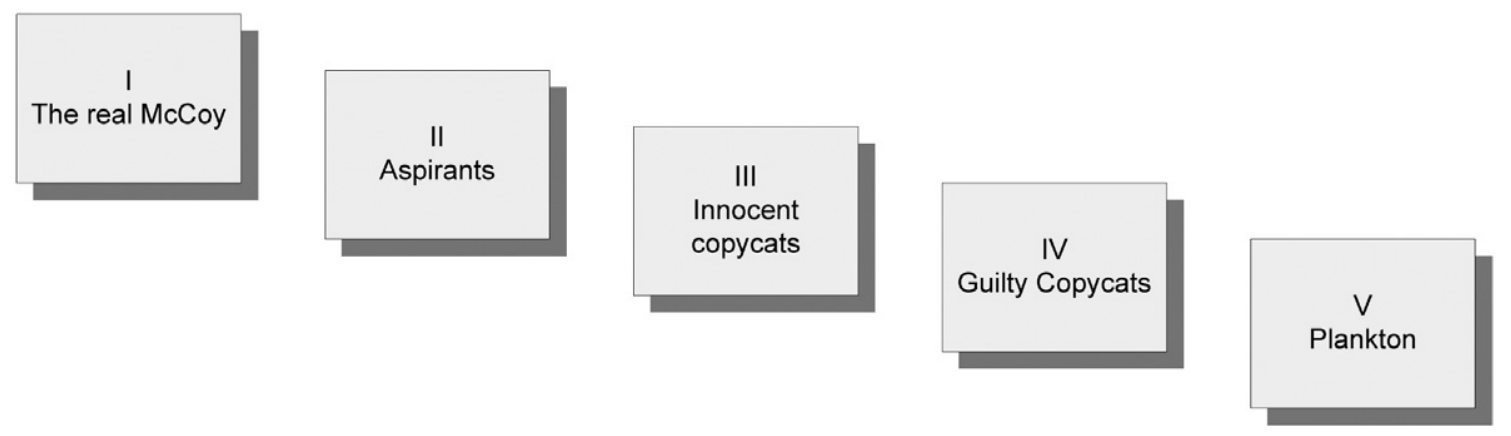

Figure 2. A Classification of Innovative SMEs

success. However, there are also factors that are known to be causes of failure - particularly lack of the competencies discussed earlier - and which should therefore convince investors to refuse funds and to advise entrepreneurs to find other avenues for their ambitions. To illustrate the thesis of this paper, we consider the results of part of a research project undertaken by Millar and Udalov (2011) to contribute to the identification of such situations. This encompassed a performance analysis of 120 companies that were successful in raising finance in Europe and the US (including both VC funding and significant grants).

While successes were easily recorded, failures, mismanagement and lack of competencies were harder to uncover. Using criteria from the management literature, the companies were divided into five types which were labelled as shown in Figure 2. The data confirmed the importance of the characteristics identified in the literature cited above and specifically that large numbers of innoSMEs who fail do not meet the four boundary conditions in at least one respect.

Those companies which did not appear to have any of the causes of failure we have called 'Type I', or 'The real McCoy' companies. There are only very few of these; however, they attract publicity and 'followers' often 'line up' to try to emulate these leaders so it is important to avoid confusing companies that are merely followers with the 'real McCoy' companies. We trust that a typology which points to the characteristics of those companies which are not of 'real McCoy' standard can form the basis for an assessment algorithm that saves wasted resources.

With the exception of Type 1 companies, all types fall down on one or often more of the first three boundary conditions indicated above; we will explain type by type below, and indicate where else they fail. The relative size of the groups as observed in our sample of 120 was as follows: innoSMEs of Type I constitute less than 1 per cent; Type II make up around 5-7 per cent, as do Type IV companies. Type III is a larger group, of about 20 per cent, but by far the largest group is Type $\mathrm{V}$, the not-so-innovative majority of 65 per cent of innoSMEs.

Whilst Type I companies are rather unique and the real kings of innovation, they are surrounded by a larger cohort of Type II companies, the 'Aspirants' that have almost made it, almost got there. They might positively answer to even three of the conditions listed above, e.g., the right idea and/or technology and good financing, but with poor leadership or poor marketing.

We have called Type III companies 'Innocent copycats'; rather than having their own innovative ideas, they try to imitate the innovators and their innovations. In fact, the Type III group is a loose collection of subgroups, many of them follow the crowd, jump on the various bandwagons and are very sensitive to most current hypes and trends in business, in society, etc.

What distinguishes Type IV companies from Type II and III is that they are less interested in real innovation, only in being in (often subsidized) business. We call them 'Guilty copycats' and they represent a not very large but nonetheless very important group due to their modus operandi - hit and run, with one big difference: they do not run but continue to consume money from government and investors; and where they manage to get their shares listed on the stock exchange, their menu is even expanded with money from private and institutional shareholders. We believe these companies seriously exploit the information asymmetry and fall down on corporate social responsibility (CSR) and ethical behaviour.

While there are only a few Type IV innoSMEs, the large majority of SMEs claiming to be innovative is in the last group, Type V, which 
we call 'Plankton'. While they may have a few of the characteristics for success, they lack so many that they have little prospect of success. They have a very negative influence on the processes of innovation. Together with the Type IV companies, they call into question the innovation process and the quality of innovations. Their ability to attract funds is not based on realistic prospects; however, in an environment where much effort is being put into supporting innovation and/or betting on potential rather than achievement, many such firms can survive. Dealing with them consumes time and attention, the result of which is similar to that of 'noise' in a circuit or system. Wittingly or unwittingly, such SMEs undermine the trust of venture capitalists and of both private and institutional investors in the very concept of innovation as such, and make all investments appear more risky.

This typology and the quantification we report - albeit exploratory and anecdotal ought to reinforce the alertness of investors and governments to targeting their financial support on those who have least likelihood of failing. Given the strengths of Type I companies, the optimum decision might be to help other types compensate for their deficiencies, and with limited resources the best return would be expected from helping Type II companies. The question arises how the other types manage to secure financing despite the defects in their capabilities and prospects.

We posit that a reason for this state of affairs is that in the innovation environment companies use, but are also able to misuse, a potent tool in the form of concealment behind information asymmetry and self-promotion through reputation.

\section{Use and Abuse of Information Asymmetry and Reputation}

Various factors have been identified as significantly facilitating the ability of innoSMEs to attract investment. Shane and Cable (2002) point to the role of social ties in securing finance for innovators, concluding that these ties influence the selection of ventures to fund through a process of information transfer.' In doing so they reject models of investment decisions based on social obligation as 'oversocialized'; they see the key factor as being the information transfer that is facilitated by the social ties.

However, in a situation of information asymmetry, particularly of a technical or intangible nature, the existence of ties does not result in the potential investor receiving and understanding the information that is required. While the ties may engender trust as suggested below - they do not as such convey information and at best provide a means for posing additional questions and receiving reassurance that the claims made are genuine. This still leaves a gap. Furthermore, even in the absence of social ties, it is still possible for firms to find financing. Thus we concur with Shane and Cable (2002) that the investor's need for information is critical but argue that, given the absence of fully understandable information (and often the existence of scepticism about much that is being claimed by potential investees), investors must also rely on some proxy for the information desired and the assessment that would have been made of it.

Several writers have referred to the role of trust in this context. Zucker (1986) distinguishes three sources of trust - reciprocal interactions, social similarity and societal institutions. In the cases we are considering there has frequently been no previous reciprocal interaction between the parties and trust seems to arise despite lack of social similarity (e.g., between the financier and the 'geek', perhaps even a 'foreign geek'); only an institutional basis remains to explain the trust. We posit that such an institution can be found in the form of reputation. Reputation serves as a signal (Jervis, 1970; Zahra, 2005; Millar, Choi \& Millar, 2008; Schulz, Borghoff \& Kraus, 2009), which indicates to the potential investor that the claims of the potential investee can be relied upon. We acknowledge that other factors play a role in the ultimate decision whether or not to invest. However, ceteris paribus reputation has the potential to give assurance in situations of information asymmetry and help overcome the problem of finding finance.

Building reputation is key for any company (Belanger, Hiller \& Smith, 2002); reputation has been defined as the perceptions of the organization shared by its multiple constituencies over time' (Fombrun, 2000; Fombrun \& van Riel, 2004; Alessandri, Yang \& Kinsey, 2006). Suh and Houston (2010) argue that a firm's reputation ('central, enduring, and distinctive corporate associations held by individuals outside of an organization') is more important than trust in impacting buyersupplier relationships - hence possibly also investor-investee relationships. A good reputation has to be earned. It is linked over time to the image perceived by the various stakeholders, and it is strategically important that the image matches the organizational and marketing identity of the company and its chosen positioning. Faced with information asymmetry, the customer gives more credence to 
offerings from organizations which have established reputations (Henard \& Dacin, 2010; Dolfsma, 2011).

Innovative SMEs like other, larger, companies can benefit from reputation in the market as well: establishing reputation creates extra receptiveness for their innovations; its benefits are evidenced through in-depth studies of reputation issues and their impact on company profitability, ability to find markets for innovations and, last but not least, on return on investment (ROI) (e.g., Avnimelech \& Teubal, 2008; Eisenegger \& Imhof, 2008; Eisenegger, 2009; Vonwil \& Wreschniok, 2009; Gligorijevic \& Leong, 2011).

\section{Ethics and Exploitation of Reputation}

However, not all use of reputation is the same. We distinguish three types of exploitation of reputation:

(a) exploitation of reputation based on performance

(b) exploitation of reputation by association

(c) reputational hype.

In some respects, reputation is similar to the concept of 'legitimacy' (Rutherford, Buller \& Stebbins, 2009) - however, it goes beyond merely bridging an initial credibility gap and getting an audience, and creates a basis for comparison (Deephouse \& Carter, 2005). This is of particular importance in the competitive task of securing a share of a limited pool of available investment or support.

Whilst reputation offers benefits, it also demands responsibility. From an ethical point of view, a company which has established a good reputation as an innovator is in a powerful position. This brings the temptation to exploit the easier life that comes with its own success. Repeated overhyping of further innovative products or unethically marketed innovations will ultimately damage reputation but in the meantime investors and/or customers are duped. The scope for unethical conduct exists and investors need to beware of this.

Reputation based on performance is a salient and critical element in the success of really innovative companies (Type I). It is, however, characteristic of innovations that most are 'one-off' and the innoSME seldom has a 'track record' of successful innovations. It is difficult, therefore, to distinguish between a company which has the sound basis of a Type I and a company which merely happens to have had a success with a particular product but has the defects of a Type II or Type III company. In the early stages, when investment is highly critical, the reputation arising from a single success is often misleading. And in the case of both Type II and Type III companies, it is likely that the companies themselves are convinced that the reputation is evidence of their strengths even though that is not justified. Even the occasional failure does not settle the matter, since it is the ability to sustain a flow of innovative products that provides a basis for building a reputation as an innovator who can be trusted (Fukuyama, 1995). As long as a high enough proportion of new products are successful, there is a positive feedback loop and reputation steadily grows.

Reputation by association is sought through the participation in a company of individuals who are respected or the presentation of a business plan which is drawn up by a respected consultancy, commercial links with respected companies and participation in respected networks (Zahra, 2005; Schulz, Borghoff \& Kraus, 2009). By assembling a portfolio of respected people and organizations, the innoSME benefits from their reputations. Our observation is that none of this is likely to reduce information asymmetry since no new information and no new understanding of the proposition need result. In a related way, investors, like customers, tend to trust a company if it has a charismatic leader or one who has a personal association with successful products - even with other companies.

Reputational hype, consisting of claims and forecasts which imply a degree of authority and insight which is not justified, should be seen as dishonesty. It may be seen as close to some promotion that passes as acceptable in consumer advertising and defended on the grounds that once the audience becomes aware that the company is not living up to its promises, the result is a loss of reputation which should be a sufficient deterrent. The problem, however, is that in the information asymmetric context of investing in innovation, the assessment of such claims is often made on the basis of whether what is said corresponds to what the hearer/investor believes to be true; making claims and explaining proposals on the basis of alleged mastery of a current new technology or trend can make the innoSME seem to be in this sense 'correct' and be perceived as being trustworthy. In effect the innoSME is being treated as reputable even though it has only made claims and forecasts and indulged in 'blinding by science'.

The power of reputational hype is particularly noticeable in market 'bubble' situations. Type IV companies are those that particularly benefit by parroting positive assessments of potential benefits and extracting value, often 
in the form of grants and support, even though they are conscious of their own defects. Type V companies also benefit when the founders take expert advice on developing business plans and proof of concept presentations: investors tend to persuade themselves that each proposal that is in line with the accepted pattern is one that will go well despite the lack of evidence - and this leads to bubbles (Daniel, Hirshleifer \& Teoh, 2002; Hirshleifer \& Teoh, 2003; Gisler, Sornette \& Woodard, 2011).

The decision to invest may thus be strongly influenced by reputational aspects, of the people involved, of the technology they are proposing to exploit, or of the network the innoSME is part of. This makes it possible for companies which lack the full set of competencies and advantages identified above to compete with more viable prospective businesses in attracting capital. Such a cause of distortion applies to all of the three latter types in our framework, but its impact is greatest through the support it provides for the sea of plankton companies in Type V.

The process has a striking similarity with that in another market governed by asymmetric information, the market for second-hand cars as described by Akerlof in 1970 in his seminal work "The Market for "Lemons"'. The results are similar for, for example, scientific and technological innovations: the quality of the invention or technology ceases to be the basis for obtaining finance and a proposal with a poor scientific basis (or even without such a basis) and/or insufficient capacity to succeed manages to get an investment due to reputation not related to the actual innovation and capacity. As a result, the process of innovation financing become distorted and unbalanced.

\section{The Ethical Challenge}

Bringing together the strands of information asymmetry and reputational hype, we identify the threat posed by the groups of SMEs which, in spite of their fundamentally unsustainable basis, manage to establish or prolong their existence by generating unrealistic expectations on the part of investors. The shortcomings described above are ones which exist at the outset of the innoSME's search for funding; hence in principle it is possible to enquire about them and in many cases take account of them before funding is given. The ability of innoSMEs to secure funding despite shortcomings therefore requires explanation and justification.

1. The body of management literature referred to above pointing to causes of failure is so substantial that we reject the conclusion that it is wrong and is ignored simply because investors who ignore it are as likely to make successful investments as any others.

2. A second possibility is that investors have been aware of the investees' deficiencies and have invested in the expectation of being able to compensate for these through intervention or guidance. In this they would take a view similar to that of support mechanisms (e.g., those financed by governments) which are typically set up on the basis that deficiencies can be recognized and once recognized can be compensated for. Inasmuch as this perception is correct, it follows that resources devoted to supporting Type II innoSMEs are a more economic - and probably more effective - route to promoting successful innovation than resources devoted to Type III, IV or V companies.

3. The third alternative is that investments have been made without recognition of the extent or nature of the deficiencies - as would be the case if in a situation of information asymmetry the investor had relied on signals (Jervis, 1970).

The consequence in the latter two cases is that when resources are devoted to Type III-V innoSMEs, the level of successful innovation is lower and resources are wasted in the sense that they achieve less than was intended and was possible.

We take the position that, from an ethical point of view, it is important to minimize the waste of resources and the disappointment not to mention other personal penalties - that arise from investment and support being directed at SME companies which do not succeed. Viewed from the broader perspective of a world in which innovation is a positive force, support which is given to innoSMEs which fail is a cause for concern as such. The failures feed scepticism about the ability of firms to innovate successfully (and insofar as state support is publicly recognized, about state support). While an ethical perspective is often ignored in discussions of business evolution we feel that the scope for deliberate deceit and waste of precious resources in this case makes it appropriate. In this we also follow the example of Nijhof and Fisscher in placing business studies in the context of a socially responsible world view (Nijhof, Fisscher \& Looise, 2002).

While we are aware of the argument that entrepreneurs who 'bend the rules' may be able to justify their actions in terms of virtue ethics (Brenkert, 2009), this is not a widely sup- 
ported view and we do not believe that the differences among the variety of ethical systems proposed otherwise in a business context make a great difference in the cases we describe. A suitable reference point for assessing ethical acceptability would be a 'ruleutilitarian' ethic, i.e., one which places the highest value on the achievement of outcomes beneficial to human society but combines this with the need to seek out rules of conduct and which thereby 'does a better job than its rivals of matching and tying together our moral convictions, as well as offering us help with our moral disagreements and uncertainties' (Hooker, 2000). We do not believe that a rule permitting deliberate deception can be accommodated in such a framework, and also feel that virtue if not rules will prescribe caution rather than unfettered abandon in initiating ventures which could be harmful to others either directly or through societal effects.

Support for innovation is a transfer of resources from the rest of the economy towards a particular group of companies. This applies even if the resources come from investors rather than the state. The justification for this in economic terms depends on the effectiveness with which the transferred resources are targeted; if this is poor then the resources might be better left with those from whom they were obtained, or used in other ways. Similarly from a consequentialist ethical viewpoint - including most varieties of utilitarianism - it is undesirable, hence unethical, to create a situation in which such sub-optimal decisions are taken, since they reduce the future well-being of the community. There is an ethical imperative to avoid this as long as that does not lead to a greater adverse consequence.

In the case of innoSMEs specifically, where such firms are the brainchild of individuals and where they commit both resources and self-respect to the endeavour, the personal loss resulting from misplaced encouragement and support needs to be added to the economic dis-benefit. We point to the existence of altogether large numbers of companies in Types III, IV and V and pose the question whether support for these results is justified in ethical terms.

There is not only the direct consequence to consider. In addition to the indefensibility from the viewpoint of utilitarian ethics of funding organizations that will inevitably fail, we also note that such failure increases the prevalence of poor average performance which in turn raises barriers to genuine, valuable and potentially successful innovation through higher cost of capital and less open- ness to innovations among customers. Furthermore, the effect of directing investment and support towards enterprises which seek to emulate those who achieved rapid and spectacular rewards from their innovations will, in our view, steer the balance of aspirations in society in the direction of securing high rewards from exclusive proprietorial innovations, and away from open, co-operative relationships and reward based on diligence, commitment and competences. It is to be expected that this will lead to individuals with the latter values being undervalued and even having difficulty in finding institutions in which they can work effectively.

Our conclusion is that the information asymmetry that is inherent in the innovation context creates a serious dilemma, a temptation to unethical behaviour, and that reputation, ceteris paribus, is an inadequate basis for making investment or purchasing decisions. The typology of innovative SMEs we have developed highlights the risks of ignoring this, particularly as it can lead to an unethical allocation of resources.

\section{Implications}

Given the ethical as well as economic issues at stake, there is a strong imperative to conduct further research which may throw light on the early warning signs that can indicate probable failure and research which can explain the behaviour of investors when faced with information asymmetry.

While investors and governments continue to have a direct self-interest in this area, the academic community might contribute by providing a broader theoretical framework. This might be assisted by revisiting techniques for comparative assessment of companies' future performance that have fallen from favour or are found too complex for non-academic audiences. In particular, it could be useful to consider an extended version of the analysis once applied by Michael Robert Milken to evaluate the performance of 'blue chip' companies as compared to companies below the investment grade, which resulted in the so-called junk bonds (Sobel, 1993).

We also draw attention to one of the important tools in creativity management, the Theory of Inventive Problem Solving, also known as TRIZ. Whilst it was initially designed to assist inventors and engineers in the solution of technical problems, currently the area of applicability of TRIZ has gone far beyond the border of engineering science. TRIZ was successfully applied to reputational analysis (Lin, Lee \& Dadura, 2011), where the 
authors used the TRIZ contradiction matrix to determine inventive principles to formulate strategies for reputation analysis in certain branches of industry. Whilst this is one particular example of using TRIZ outside its main areas of technology-related applications, the number of these examples is growing, especially in the South-East Asia context (Lee \& Leu, 2010; Zouaoua et al., 2010; Breja \& Banwet, 2011; Zhang \& Sang, 2011; Zhang \& Zhang, 2011).

Through the development of analytical and TRIZ-like expert frameworks and using appropriately trained professionals (Medina, Lavado \& Cabrera, 2005; Moehrle, 2005; Alves et al., 2007; Zhang \& Xu, 2007; Forest \& Faucheux, 2011; Gadd, 2011), it is argued that a procedure may be developed which will perhaps not reveal all the best candidates for investment, nor by definition create innovative champions, but would more effectively eliminate much undesirable 'noise' from the innovative investment market.

\section{Conclusions, Limitations and Areas for Further Research}

Innovations are important, but many innovative SMEs that receive funding then fail. In the meantime, many others are unable to find funding or support. The ability of firms to attract support even though they lack the basics to succeed requires explanation and evaluation. We analysed the concept of information asymmetry and pointed to its special relevance in the case of innoSMEs' relationship with investors. Information asymmetry was seen to be relevant in two ways:

(a) Investors are often unable to verify claims about the quality of the innovation or the company and are thus led astray - whether deliberately or not.

(b) A proxy/signal for the quality of an innoSME, available in the form of reputation, allows companies to secure support despite relative secrecy about matters that might deter the investor.

We reported on a typology of innoSMEs which emerged from an on-going business performance analysis of 120 innoSMEs that had been successful in obtaining funding and were able to bring the above points to life by discussing the way in which they made possible the progress of companies across the range covered by the typology. We noted that the behaviour of those promoting innoSMEs which had poor or no prospects of success need not always be unethical in that entrepreneurs have been shown to be prone to unrealistic expectations and referred in passing to Brenkert (2009)'s view that a strict rule-based ethic is not always appropriate. It appeared that deliberate deception - Type IV companies - was rarer than excessive hype and self-deception.

None the less, the high proportion of potential investees with poor prospects results in the investment market coming under pressure, which we see as 'noise' interfering with its optimal functioning. We therefore argued that given the nature of the innovation process and of the founders and promoters of innoSMEs, investors need to take account of the danger of diverting resources which it would be more ethical to direct elsewhere. We argued that a better understanding of information asymmetry and its significance in this area could lead to the development of better tools for selecting innoSMEs for investment. Our conclusion is that there is an argument based on economics and ethics for more research in this area and, in the meantime, a better recognition of the dangers of information asymmetry in the form of a relevant critical assessment of the information provided by those seeking funding.

For innovative SMEs we conclude that, in an environment where there is competition for support, there is value in establishing reputation, particularly where the technical or IPR nature of the proposed innovation makes it difficult for investors to validate claims. While reliance on reputation may be subjected to greater scrutiny, as long as the proportion of successes is sufficient, there is a positive feedback loop. These considerations also bring into focus the responsibilities of innovative companies. The links between social responsibility of innovative companies, their ability to innovate and to show outstanding business performance are not always clear, but they do exist (Fisscher \& Nijhof, 2005; Fisscher et al., 2005). For the entrepreneurs and executives of innoSMEs, there is a need to reflect or conduct internal ethical dialogue (Nijhof, Fisscher \& Looise, 2000) about both the methods and the wider effects of their attempts to obtain funding.

There is a limitation to this paper in as much as it invokes a perspective on the causes of corporate failure which is normally applied to firms much larger than the innovative SMEs considered here. The discussion of information asymmetry is also framed at a general level rather than considering the different types of information that are relevant to the information decision. We accept that there is also information asymmetry in the opposite direction between the innoSME and the investor inasmuch as the investor is better informed as to general availability of finance and the 
conditions that can be attached to an investment. None the less, we believe that the phenomenon of excessive failure rates and the relevance of information asymmetry are well enough established to merit consideration of whether the arguments here are of general validity.

The typology used to illustrate the situation addressed by our ethical concerns may also be considered a limitation. While it was based on researching the operations of 120 innovative SMEs in the technology field in Europe and the USA, results - particularly as regards the proportions of firms of each of the types - may be different in other innovative areas and further research on such topics would be justified.

In the choice of paradigm for our ethical considerations we believe that we have aligned ourselves with the approaches most consistent with current CSR and other business thought. However, it is conceivable that some virtue ethics and rule-based approaches could reject the need for further research on those providing investment and support on the grounds that their actions need to be based on principles that are independent of outcomes and consequences and that the only ethical issues are for the innoSMEs. A strand of ethical research on innoSMEs might none the less be called for to consider the obligations of innoSMEs, and this could include the question of whether they ought not to be attempting to raise funds if they lack the characteristics to succeed.

As is argued in the conclusions above, further research is also justified on the signals, indices and proxies used by investors to overcome information asymmetry problems and on the extent and nature of would-be investees' responses in the form of manipulation of such signals as reputation. We referred to some techniques from investment analysis which might form the starting point for improved evaluation techniques, e.g., TRIZ.

We suggest that consideration of approaches to information asymmetry coupled with our categorization forms a useful starting point for testing theory development in this area and as indicated above we are continuing our research in understanding better the intricacies of the five innovation types distinguished.

\section{Note}

1. We recognize that companies with a sophisticated understanding of patent law may pursue different disclosure strategies as competitive weapons, but this is generally not relevant for or appealing to SMEs with limited funds.

\section{References}

Aghion, P. and Griffith, R. (2008) Competition and Growth: Reconciling Theory and Evidence. MIT Press, Cambridge, MA.

Akerlof, G.A. (1970) The Market for 'Lemons': Quality Uncertainty and the Market Mechanism. The Quarterly Journal of Economics, 84, 488-500.

Alessandri, S.W., Yang, S.-U. and Kinsey, D.F. (2006) An Integrative Approach to University Visual Identity and Reputation. Corporate Reputation Review, 9, 258-70.

Alves, J., Marques, M.J., Saur, I. and Marques, P. (2007) Creativity and Innovation through Multidisciplinary and Multisectoral Cooperation. Creativity and Innovation Management, 16, 27-34.

Aumann, R.J. (1976) Agreeing to Disagree. The Annals of Statistics, 4, 1236-9.

Avnimelech, G. and Teubal, M. (2008) From Direct Support of Business Sector R\&D/Innovation to Targeting Venture Capital/Private Equity: A Catching-Up Innovation and Technology Policy Life Cycle Perspective. Economics of Innovation and New Technology, 17, 153-72.

Bartoloni, E. (2011) Capital Structure and Innovation: Causality and Determinants. Empirica, $1-41$.

Belanger, F., Hiller, J.S. and Smith, W.J. (2002) Trustworthiness in Electronic Commerce: The Role of Privacy, Security, and Site Attributes. Journal of Strategic Information Systems, 11, 245-70.

Berger, R. and Herstein, R. (2012) The Limits of Guanxi from the Perspective of the Israeli Diamond Industry. Journal of Chinese Economic and Foreign Trade Studies, 5, 29-42.

Breja, S.K. and Banwet, D.K. (2011) Developing a Creative-Inventive Framework for Strategic Management and Sustainable Business Excellence. International Journal of Productivity and Quality Management, 8, 1-32.

Brenkert, G.G. (2009) Innovation, Rule Breaking and the Ethics of Entrepreneurship. Journal of Business Venturing, 24, 448-64.

Chesbrough, H.W. (2003) Open Innovation: The New Imperative for Creating and Profiting from Technology. Harvard Business School Press, Boston, MA.

Christensen, S.L., Schwartz, R.G. and Hoss, M.A.K. (2008) Ethical Entrepreneurs: A Study of Perceptions. International Journal of Entrepreneurship and Small Business 6, 114-32.

Daniel, K., Hirshleifer, D. and Teoh, S.H. (2002) Investor Psychology in Capital Markets: Evidence and Policy Implications. Journal of Monetary Economics, 49, 139-209.

Darby, M.R. and Karni, E. (1973) Free Competition and the Optimal Amount of Fraud. Journal of Law and Economics, 16, 67-86.

Deephouse, D.L. and Carter, S.M. (2005) An Examination of Differences Between Organizational Legitimacy and Organizational Reputation. Journal of Management Studies, 42, 329-60.

Dolfsma, W. (2011) Appropriability, Services and Reputation. Technology Analysis and Strategic Management, 23, 919-30.

Eisenegger, M. (2009) Trust and Reputation in the Age of Globalisation. In Klewes, J. and 
Wreschniok, R. (eds.), Reputation Capital. Springer, Berlin, pp. 11-22.

Eisenegger, M. and Imhof, K. (2008) The True, the Good and the Beautiful. Reputation Management in the Media Society. In Zerfass, A., Ruler, B. and Sriramesh, K. (eds.), Public Relations Research. VS Verlag für Sozialwissenschaften, Berlin, pp. 12546.

Enkel, E., Gassmann, O. and Chesbrough, H. (eds.) (2010) Special Issue: The Future of Open Innovation. RED Management, 40, 213-343.

Fassin, Y. (2000) Innovation and Ethics Ethical Considerations in the Innovation Business. Journal of Business Ethics, 27, 193-203.

Fisscher, O. and Nijhof, A. (2005) Implications of Business Ethics for Quality Management. TQM Magazine, 17, 150-60.

Fisscher, O., Frenkel, D., Lurie, Y. and Nijhof, A. (2005) Stretching the Frontiers: Exploring the Relationships between Entrepreneurship and Ethics. Journal of Business Ethics, 60, 207-9.

Fombrun, C.J. (2000) Reputation: Realizing Value from the Corporate Image. Harvard Business School Press, Boston, MA.

Fombrun, C.J. and van Riel, C.B.M. (2004) Fame and Fortune: How Successful Companies Build Winning Reputations. Pearson Education, Upper Saddle River, NJ.

Forest, J. and Faucheux, M. (2011) Stimulating Creative Rationality to Stimulate Innovation. Creativity and Innovation Management, 20, 207-12.

Forsythe, J. and Khormaei, R. (2011) Innovation Topology: The Dimensions and Their Characteristics that Drive Innovation. Proceedings of PICMET '11: July 31 2011-August 42011 Technology Management in the Energy Smart World, pp. 1-10.

Freeman, C. and Soete, L. (1997) The Economics of Industrial Innovation, 3rd edn. MIT Press, Cambridge, MA.

Fukuyama, F. (1995) Trust: The Social Virtues and the Creation of Prosperity. Free Press, New York.

Gadd, K. (2011) TRIZ for Engineers: Enabling Inventive Problem Solving. Wiley, Chichester.

Gisler, M., Sornette, D. and Woodard, R. (2011) Innovation as a Social Bubble: The Example of the Human Genome Project. Research Policy, 40, 1412-25.

Gligorijevic, B. and Leong, B. (2011) Trust, Reputation and the Small Firm: Building Online Brand Reputation for SMEs. Proceedings of the Fifth International AAAI Conference on Weblogs and Social Media, pp. 494-7.

Griffiths, W. and Webster, E. (2010) What Governs Firm-Level R\&D: Internal or External Factors? Technovation, 30, 471-81.

Henard, D.H. and Dacin, P.A. (2010) Reputation for Product Innovation: Its Impact on Consumers. Journal of Product Innovation Management, 27, 32135.

Hirshleifer, D. and Teoh, S.H. (2003) Herd Behaviour and Cascading in Capital Markets: a Review and Synthesis. European Financial Management, 9, 25-66.

Hooker, B. (2000) Ideal Code, Real World. Oxford University Press, Oxford.
Jeon, D.-S. and Menicucci, D. (2008) Money, Fame and the Allocation of Talent: Brain Drain and the Institution of Science. Journal of Economic Behavior and Organisation, 66, 558-81.

Jervis, R. (1970) The Logic of Images in International Relations. Princeton University Press, Princeton, NJ.

Kline, S.J. and Rosenberg, N. (1986) An Overview of Innovation. In Landau, R. and Rosenberg, N. (eds.), The Positive Sum Strategy: Harnessing Technology for Economic Growth. National Academy Press, Washington, DC, pp. 275-306.

Kuratko, D. and Brown, T.J. (2010) Emerging Life Sciences Ventures: The Quest for Legitimacy. Business Horizons, 53, 211-20.

Lee, L.J.H. and Leu, J.D. (2010) Using Value Engineering and TRIZ for Better Business Process Management. 40th International Conference on Computers and Industrial Engineering (CIE), Awaji IEEE, pp. 1-5.

Lin, L., Geng, X. and Whinston, A.B. (2005) A Sender-Receiver Framework for Knowledge Transfer. MIS Quarterly, 29, 197-219.

Lin, P.Y., Lee, T.R. and Dadura, A.M. (2011) Using Grey Relational Analysis and TRIZ to Identify KSFs and Strategies for Choosing Importers and Exporters: An Example of the Taiwanese Hand-Tool Industry. Journal of Manufacturing Technology Management, 22, 47488.

Luo, T. and Mann, A. (2011) Survival and Growth of Silicon Valley High-Tech Businesses Born in 2000. Monthly Labor Review, 9, 17-31.

Medina, C.C., Lavado, A.C. and Cabrera, R.V. (2005) Characteristics of Innovative Companies: A Case Study of Companies in Different Sectors. Creativity and Innovation Management, 14, 27287.

Millar, C.C.J.M. (2004) Witte Wieven Strikken: Entangling Spirits and Spectres: Marketing and Intangibles. Twente University Press, Enschede.

Millar, C.C.J.M. and Udalov, Y.B. (2011) Investing in InnoSMEs: a Typology. University of Twente, Mimeo.

Millar, C.C.J.M., Choi, C.J. and Millar, H. (2008) Google and Global Market Search: Information Signals and Knowledge Indices. International Journal of Technology Management, 43, 96106.

Moehrle, M.G. (2005) What is TRIZ? From Conceptual Basics to a Framework for Research. Creativity and Innovation Management, 14, 3-13.

Nayyar, P.R. (1993) Performance Effects of Information Asymmetry and Economies of Scope in Diversified Service Firms. The Academy of Management Journal, 36, 28-57.

Nijhof, A., Fisscher, O. and Looise, J.K. (2000) Coercion, Guidance and Mercifulness: The Different Influences of Ethics Programs on Decision-Making. Journal of Business Ethics, 27, 33-42.

Nijhof, A., Fisscher, O. and Looise, J.K. (2002) Inclusive Innovation: A Research Project on the Inclusion of Social Responsibility. Corporate Social Responsibility and Environmental Management, 9, 83-90. 
Rutherford, M.W., Buller, P. and Stebbins, J.M. (2009) Ethical Considerations of the Legitimacy Lie. Entrepreneurship Theory and Practice, 33, 94964.

Schulz, A., Borghoff, T. and Kraus, S. (2009) International Entrepreneurship: Towards a Theory of SME Internationalization. International Journal of Business and Economics, 9, 1-12

Schumpeter, J.A. and Opie, R. (1934) The Theory of Economic Development: An Inquiry into Profits, Capital, Credit, Interest, and the Business Cycle. Harvard University Press, Cambridge, MA.

Shane, S. and Cable, D. (2002) Network Ties, Reputation, and the Financing of New Ventures. Management Science, 48, 364-81.

Sobel, R. (1993) Dangerous Dreamers: The Financial Innovators from Charles Merrill to Michael Milken. Wiley, New York.

Suh, T. and Houston, M.B. (2010) Corporate Image and Reputation in B2B Markets. Industrial Marketing Management, 39, 744-51.

Vonwil, M. and Wreschniok, R. (2009) The CSR Myth: True Beauty Comes from Within. In Klewes, J. and Wreschniok, R. (eds.), Reputation Capital. Springer, Berlin, pp. 83-99.

Zahra, S.A. (2005), A Theory of International New Ventures: A Decade of Research. Journal of International Business Studies, 36, 20-2.

Zhang, F.Y. and Xu, Y.S. (2007) Research on Technical Strategy for New Product Development based on TRIZ Evolution Theory. International Journal of Product Development, 4, 96-108.

Zhang, Y. and Sang, X. (2011) Application of Separation Principle in Management Innovation based on TRIZ. 2011 International Conference on Computer Science and Service System (CSSS), pp. 2116-19.

Zhang, Y. and Zhang, D. (2011) The Constructing Way of Management Contradiction Solving Matrix based on TRIZ. 2011 International Conference on E -Business and E -Government (ICEE), pp. 1-4.

Zouaoua, D., Crubleau, P., Mathieu, J., Thieblemont, R. and Richir, S. (2010) TRIZ and the Difficulties in Marketing Management Applications. 2010 Proceedings of PICMET ‘10: Technology Management for Global Economic Growth (PICMET), pp. 1-10.

Zucker, L.G. (1986) Production of Trust: Institutional Sources of Economic Structure, 1840 1920. Research in Organizational Behavior, 8, 53-111.
Carla Millar (c.millar@utwente.nl) is emeritus Professor, International Marketing \& Management at the University of Twente, a Fellow of Ashridge, and a Visiting Professor at the University of Chester. Her research covers creativity, cross-cultural positioning, international branding and reputation, knowledge and intangibles, services marketing management, corporate governance, the public sector and 'women at the top' in business and academia, oftenfocusing on international business and emerging markets. She has published in, for example, Journal of Management Studies, British Journal of Management, Management International Review, Journal of Business Ethics and Journal of Organizational Change Management, and currently guest edits special issues for Journal of Organizational Change Management, Journal of Public Administration and Journal of Management Development on the Sustainability Challenge and has (co)authored five books, including Emergent Globalisation (2005), Knowledge Entanglements (2006) and Ethical Leadership: Global Challenges and Perspectives (2010).

Yuri Udalov has a PhD in physics and published about 80 articles in peerreviewed journals such as Applied Physics Letters, Journal of Applied Physics, IEEE Journal of Quantum Electronics and conference proceedings, co-authored a book Frequency-Selective Gas Laser (1992) and holds four patents. He successfully combines academic research with business activities. In 2004 he won the best business plan prize in the annual competition 'New Venture' organized by McKinsey and the Dutch Ministry of Economics. His research interests in the humanities include sociology, social psychology and applied management science.

Hartley Millar has a doctorate in philosophy from Oxford University and has spent several decades as a management consultant working with major companies, government agencies and start-ups. He has published in Mind, Journal of Business Ethics and other academic journals as well as professional publications. He has led the development of corporate governance guidelines for inter-company joint ventures and is currently working on philosophical research to provide foundations for a theory of governance. 